$\begin{array}{ll} & \text { Etnográfica } \\ \text { etnográfica } & \text { Revista do Centro em Rede de Investigação em }\end{array}$

Antropologia

vol. $13(2) \mid 2009$

Vol. $13(2)$

\title{
Apresentação
}

\section{Jean-Yves Durand}

URL: https://journals.openedition.org/etnografica/1314

DOI: 10.4000/etnografica.1314

ISSN: 2182-2891

\section{Editora}

Centro em Rede de Investigação em Antropologia

\section{Edição impressa}

Data de publição: 1 novembro 2009

Paginação: 467-468

ISSN: 0873-6561

\section{Refêrencia eletrónica}

Jean-Yves Durand, «Apresentação», Etnográfica [Online], vol. 13 (2) | 2009, posto online no dia 17 janeiro 2012, consultado o 12 fevereiro 2022. URL: http://journals.openedition.org/etnografica/1314 ; DOI: https://doi.org/10.4000/etnografica.1314

\section{(c) (i) (9)}

Etnográfica is licensed under a Creative Commons Attribution-NonCommercial 4.0 International License. 


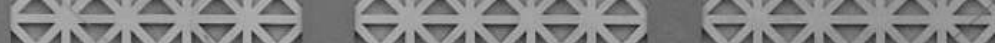

\section{Apresentação}

\section{Jean-Yves Durand}

Universidade do Minho, CRIA

E mora digam praticar uma disciplina agora deliberadamente virada para a
contemporaneidade, continua a ser algo raro ver antropólogos participarem em debates cidadãos na sua qualidade de cientistas sociais. A presença da disciplina na esfera pública é muito variável consoante os países e os momentos. Em Portugal, a sua imagem pública (para quem tem uma) continua a evocar em exclusivo o universo rural ou mundos exóticos, "tribos" e "tradições", "crenças" e "artesanato"... Há uma certa ironia no facto de ter sido em relação a um objecto ligado a parte desta nebulosa, o Museu de Arte Popular (MAP), que vários antropólogos portugueses deram recentemente a cara, mesmo se alguns deles (João Leal, Vera Marques Alves e Sónia Vespeira de Almeida) mostram precisamente que o passadismo associado ao MAP tem de ser reavaliado. E deve ser por ter dirigido um estudo sobre os lenços de namorados, objectos que foram aproveitados com criatividade pelos defensores do MAP, que fui solicitado várias vezes para participar no protesto contra a decisão do governo (apresentada nos artigos seguintes). Acontece que a minha posição era muito mais matizada. Claro, num mundo perfeito, seria possível musealizar o MAP como testemunho de um momento cultural marcante do século XX em Portugal. Ou talvez não. Num mundo perfeito o Estado Novo nunca teria existido e, portanto, o MAP também não.

Mais seriamente, será que uma tal metamusealização historicista, cujo interesse documental não se discute no absoluto, faz sentido no contexto económico, cultural e museológico actual (Paulo Ferreira da Costa)? (O interesse, no mesmo contexto, de um museu Mar da Língua Portuguesa destinado a substituir o MAP é outro assunto que importa discutir independentemente.) O argumento de que "hoje tudo é património" (João Leal) chega realmente para justificá-la do ponto de vista de uma ciência social crítica confrontada com a vertigem patrimonializadora das sociedades contemporâneas? A continuidade da ligação entre as colecções e a sua cenografia (Vera Marques Alves e Sónia Vespeira de Almeida), quando esta pode ser registada, é realmente necessária? Fazer do MAP um pólo de dinamização directa da criatividade cultural e talvez 
económica: mas como, concretamente? Não há inúmeras outras instituições com este papel? Já que passaria assim a distinguir-se de um museu tal como entendido habitualmente, o que seria então? Este último ponto é talvez o mais estimulante de toda a questão: num momento em que numerosos países europeus estão a repensar, com dificuldade, o papel dos seus museus etnográficos, o caso do MAP pode espoletar uma reflexão comparável em Portugal (Paulo Ferreira da Costa), onde parece cada vez mais urgente e inevitável.

A Etnográfica não tem vocação jornalística, mas achámos importante acompanhar e reagir, com a celeridade possível por parte de uma revista académica, aos acontecimentos da vida de um museu que nos diz directamente respeito (toda a situação mudou durante o Verão, com a reabertura do processo de classificação do edifício). Fortes constrangimentos de calendário e de espaço não permitiram dar ao dossiê todo o desenvolvimento desejado, começando por esta brevíssima apresentação, que se previu inicialmente como um artigo inteiro: as opiniões contraditórias e as interrogações apontadas aqui estão longe de ser exaustivas. A Comissão Editorial espera vivamente que sejam o ponto de partida para um debate alargado entre os nossos leitores, cujas contribuições são agora esperadas.

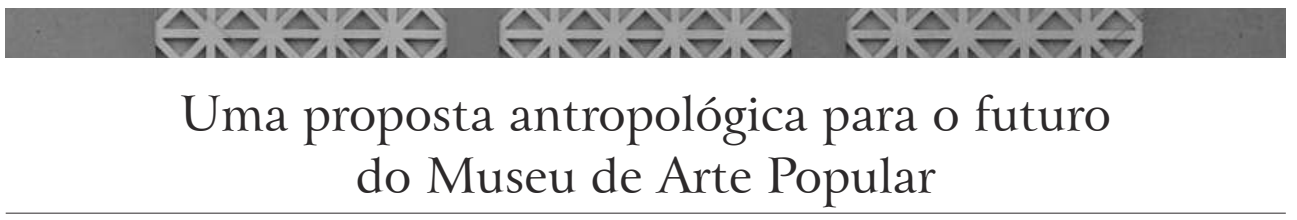

Sónia Vespeira de Almeida e Vera Marques Alves

FCSH-UNL, CRIA / CRIA

os anos 80, James Clifford (cf. 1988: 229) regozijava-se com o abandono
do projecto de modernização da "Boas Room of Northwest Coast Artifacts" do Museu Americano de História Natural. E isto porque essa sala, com a sua configuração e atmosfera datadas, desvendaria um momento particular do interesse pelos objectos não ocidentais. Aliás, adiantava ainda Clifford, qualquer exposição de antropologia deveria tornar visíveis as condições históricas que levaram à constituição da colecção exibida. Este posicionamento evidenciaria, antes de mais, a forma como antropólogos, artistas e públicos se coleccionavam a si próprios e ao mundo.

Em 2006, o Ministério da Cultura anunciou o encerramento do Museu de Arte Popular (MAP) de modo a instalar no seu edifício o Museu da Língua 
Portuguesa. Neste artigo apresentamos alguns argumentos que explicam porque é que esta decisão é um erro. A extinção do MAP, mantendo, por um lado, a integridade exterior do edifício, implicaria, por outro, a ocultação dos murais que decoram as suas paredes interiores, o armazenamento de parte do seu mobiliário original noutras instituições e a deslocação da sua colecção para o Museu Nacional de Etnologia (MNE). Desmembrar-se-ia, assim, uma unidade museológica que se mantivera quase inalterada desde os anos 40 , cujos diferentes elementos - arquitectura, decoração interior, arranjo expositivo e colecção - foram concebidos em conjunto, só ganhando significado em relação mútua.

Tal como Clifford defendeu a necessidade de manter a configuração inicial da "Sala Boas", também nós propomos a preservação do MAP, sugerindo a sua musealização de modo a dar a ver as ideias e valores que estiveram subjacentes à sua criação. O museu pode, assim, tornar-se não só um lugar de reflexão sobre as conotações ideológicas da arte popular durante o Estado Novo, mas também um instrumento decisivo para a compreensão de outras etapas do interesse intelectual e ideológico pela cultura demótica ao longo dos séculos XIX e XX. Em última instância, é a própria ânsia contemporânea pelo autêntico e pelo genuíno através do popular que pode ganhar um espaço ideal de interrogação crítica.

Só recentemente começou a perceber-se a complexidade de sentidos que o MAP incorpora. Durante longos anos, o museu foi vítima de um processo de negligência, de ordem museológica e científica, que resultou na ausência de informação, quer sobre os mecanismos que acompanharam a constituição da sua colecção, quer sobre o contexto intelectual e político que lhe conferiu um determinado formato. Inaugurado em 1948 pelo Secretariado da Informação, Cultura Popular e Turismo (SNI) - o órgão do Estado Novo responsável pela propaganda e política cultural do regime -, o MAP tem sido várias vezes reduzido a um produto acabado da ideologia ruralista e passadista de Salazar, imagem que empobrece e lesa a compreensão do que é o museu e do que foram as ideias e processos históricos que explicam o seu aparecimento. O MAP veiculava uma imagem do povo que ia ao encontro do projecto social e político do regime, mas essa imagem não devia menos à vivência modernista e cosmopolita de António Ferro, primeiro director do SNI.

Com efeito, o MAP foi o culminar de uma política folclorista que começou a ser concebida por Ferro ainda nos anos 20, tendo sido depois sistematicamente desenvolvida no quadro da actividade do SNI. A grande preocupação que orientou essa política, e nessa medida o projecto do próprio museu, foi a da afirmação de Portugal como uma nação moderna, mas distinta de todas as outras. No desenho dessa "distinção", a arte popular portuguesa teria uma vantagem em relação ao culto das glórias do passado pátrio: falaria de uma nação plena de vitalidade que não vivia apenas da grandeza pretérita (cf. Alves 2008). É neste contexto que a colaboração dos artistas modernos nas acções 
de carácter etnográfico do SNI é tão significativa. Colocando o arranjo expositivo e pinturas murais interiores do MAP nas mãos da equipa de pintores decoradores do SNI e atribuindo ao arquitecto modernista Jorge Segurado a responsabilidade da transformação da estrutura da Secção da Vida Popular da Exposição do Mundo Português no edifício do museu, António Ferro impedia assim que a arte popular fosse um mero sucedâneo do culto das antiguidades históricas. Por isso, separar os objectos expostos no museu do seu contexto original, relegando-os para outro espaço, prejudicaria profundamente a capacidade de compreensão das ideias que estiveram subjacentes à criação daquela colecção.

A aproximação de António Ferro à arte popular - em que o moderno e o tradicional se misturavam - era já patente em 1921, quando o escritor promovia a constituição de bailados modernos portugueses inspirados nas danças e trajos populares. Ganharia novo fulgor no encontro de Ferro com os modernistas brasileiros na Semana Moderna de São Paulo, na sua vista às Exposições Internacionais dos anos 20 ou nas suas viagens a Barcelona e Bucareste em 1929 (cf. Alves 2008). O MAP testemunha, de resto, uma opção que esteve longe de constituir uma estratégia isolada de Portugal, mas que, pelo contrário, dominou vários processos de afirmação nacional nos anos 30 e 40 (cf., por exemplo, Whisnant 1983). Para a sua compreensão é tão importante ter em conta as condicionantes da vida cultural e política portuguesa da I República e do Estado Novo como, por exemplo, a influência do pensamento de intelectuais franceses de entre-guerras, como Valéry ou Duhamel, para quem a grande preocupação era a diluição das diferenças culturais no âmbito de uma modernização supostamente massificadora (cf. Peer 1998).

Recuperar o museu não seria, assim, devolvê-lo à morte lenta em que o mesmo se encontrava, mas transformá-lo num instrumento de pensamento crítico e reflexivo, através da manutenção dos vários elementos que o compõem, bem como de numa agenda sólida de exposições temporárias que ajudasse a desvelar o variado conjunto de relações entre ideias, pessoas e instituições que contribuíram para a constituição daquela colecção.

O museu conduz-nos desde logo à complexidade de usos ideológicos a que a cultura popular foi submetida na primeira metade do século XX, no âmbito quer dos projectos de afirmação nacional, quer dos processos de construção social das elites e das classes médias. A política folclorista do SNI incorpora uma tendência mais ampla da história cultural do século XX, que se traduz na integração dos objectos da arte popular - e também os da arte primitiva - na vivência de certos grupos intelectuais e da burguesia cultivada, tornando-se essencial para o estudo deste processo.

Por outro lado, o MAP serve como pano de fundo para iluminar outros momentos da história das apropriações do popular em Portugal. Desde logo, o Museu de Arte Popular tem de ser relacionado com o movimento de descoberta 
da arte popular que começou em finais do século XIX, com escritores como Ramalho Ortigão e historiadores de arte como Joaquim de Vasconcelos, e sobretudo com a I República. A colecção de objectos de arte popular apresentada foi de facto reunida com base num trabalho de inventariação prévio, realizado pela etnografia dos anos 10 e 20 (cf. Leal 2006; Alves 2008).

O MAP convida, também, à reflexão em torno das opções do grupo de Jorge Dias e de todo um conjunto de agentes que durante o Estado Novo empreenderam buscas pelo popular - e que desafiaram a imagem cénica da nação -, como, por exemplo, os agrónomos do Inquérito à Habitação Rural lançado no final dos anos 30, os artistas e escritores do movimento neo-realista, os arquitectos do Inquérito à Arquitectura Popular nos anos 50 (cf. Leal 2000), não esquecendo as recolhas de música de Lopes Graça e Michel Giacometti.

Mas o museu permite-nos ir mais além, na medida em que constitui como que uma plataforma de indagação de todo um conjunto de movimentos em torno do "povo", empreendidos nos anos agitados e urgentes da revolução de 1974, que procuram fazer a ruptura com a concepção estadonovista da cultura popular (cf. Almeida 2009). Destas iniciativas destaca-se o Plano de Trabalho e Cultura coordenado por Michel Giacometti no âmbito do Serviço Cívico Estudantil (1974-1977), que assumidamente procurou combater a imagem idílica e pacífica da ruralidade exibida nas salas do Museu de Arte Popular (cf. Branco 1993).

É neste contexto que o MAP nos situa perante as mundividências de um conjunto de agentes diferenciados num arco temporal alargado que se prolonga até à actualidade. A sua colecção confronta-nos deste modo com a "agência" e os trânsitos de um conjunto particular de objectos. Dos seus locais de origem foram transportados para as salas do Museu de Arte Popular, habitando agora o Museu de Etnologia. São objectos viajantes que ocupam as páginas dos jornais nacionais, como um exemplar da cerâmica de Nisa que foi convocado para ilustrar a entrevista de Joaquim Pais de Brito ao Público (9 de Julho de 2009). Nesta fotografia, ampliada, podemos observar uma etiqueta com indicações manuscritas resultantes do processo de inventariação levado a cabo pelo MNE. Desta nova morada esperamos que a colecção, com cerca de 25.000 objectos, regresse ao edifício do Museu de Arte Popular para que, no futuro, possa dialogar com os outros usos do popular.

\section{BIBLIOGRAFIA}

ALMeIDA, S. V. de, 2009, Camponeses, Cultura e Revolução: Campanhas de Dinamização Cultural e Acção Cívica do MFA (1974-1975). Lisboa, IELT e Colibri.

ALVES, V.M., 2008, “Camponeses Estetas” no Estado Novo: Arte Popular e Nação na Política Folclorista do Secretariado da Propaganda Nacional. Lisboa, ISCTE, tese de doutoramento. 
BRANCO, J.F., 1993, "Ciência e povo: a construção de universos camponeses", em J.F.

Branco e L. T. de Oliveira, Ao Encontro do Povo - I: A Missão. Oeiras, Celta Editora, 235-252 .

CLIFFORD, J., 1988, The Predicament of Culture: Twentieth-Century Ethnography, Literature and

Art. Cambridge e Londres, Harvard University Press.

LEAL, J., 2000, Etnografias Portuguesas (1870-1970): Cultura Popular e Identidade Nacional.

Lisboa, Publicações Dom Quixote.

—_, 2006, Antropologia em Portugal: Mestres, Percursos, Transições. Lisboa, Livros Horizonte.

PEER, S., 1998, France on Display: Peasants, Provincials, and Folklore in the 1937 Paris World's

Fair. Albany, State University of New York Press.

WHISNANT, D.E., 1983, All That is Native and Fine: The Politics of Culture in an American

Region. Londres e Chapel Hill, The University of North Carolina Press.

Da arte popular às culturas populares híbridas ${ }^{1}$

João Leal

FCSH-UNL, CRIA

Costaria de apresentar dois argumentos principais em defesa do Museu de

$\checkmark$ Arte Popular (MAP), que o presente governo, mal-avisado, decidiu encerrar. O primeiro diz que, num quadro - como o que caracteriza a contemporaneidade - em que tudo se tornou susceptível de patrimonialização, faz todo o sentido encarar o MAP como um património que deve ser defendido ou, para ser mais específico, como um museu que deve ser musealizado. O segundo argumento diz que, num quadro - como o que caracteriza a contemporaneidade - em que as culturas populares têm vindo a ser reformatadas a partir de ideias como a hibridez e a criatividade, faz todo o sentido dinamizar o MAP, fazendo dele uma plataforma de diálogo com essas novas formas da cultura popular. O primeiro argumento extrapola para o caso do MAP ideias sobre o património defendidas por historiadores como Pierre Nora (1984) e David Lowenthal (1998). O segundo tira consequências de debates sobre as culturas populares pós-modernas, protagonizados por antropólogos como Nestor García Canclini (1998) ou David Guss (2000). 
De acordo com o primeiro argumento, tudo hoje é património. A prova de que é assim é dada justamente pela ideia em nome da qual se quer destruir o MAP: a constituição de um Museu da Língua (e do Mar...). A ideia, como se sabe, não é original. É importada do Brasil e faz parte das guerras culturais em curso acerca da propriedade da língua portuguesa. Mas não é esse o ponto que eu queria sublinhar. A simples ideia da criação de um Museu da Língua seria impensável há duas décadas. E se hoje é aceite com naturalidade, é porque aquilo que contemporaneamente se entende por património ganhou uma amplitude e um eclectismo que possibilitam que tudo - ou quase tudo - seja visto como património, ou para citar Pierre Nora (1984), que tudo - ou quase tudo - seja visto como um lugar de memória. Segundo Marc Augé (2006), o mundo pós-moderno e globalizado em que vivemos é um mundo assente na multiplicação de não-lugares. Exactamente por isso - em reacção a isso -, é também um mundo assente na multiplicação de lugares de memória, de património, de kastom (como se diz no pidgin English da Melanésia), de heritage (como se diz em inglês), de tradições (inventadas ou não).

O MAP é, no caso português, um desses lugares de memória. Ele é, antes do mais, o lugar de cristalização de uma tradição de estudos, de coleccionismo e de intervenção sobre a arte popular que nasce no final do século XIX com Joaquim de Vasconcelos, que se prolonga na I República com Vergílio Correia, Luís Chaves ou Leite de Vasconcelos, e que culmina - mas não termina - no Estado Novo com a actividade de António Ferro no SPN/SNI. Crítica, a esquerda posicionou-se também nesta área, propondo - por exemplo com Ernesto de Sousa - uma arte popular alternativa, apoiada na chamada outsider art. Esta importância atribuída à arte popular não é especificamente portuguesa e nada tem de provinciano: em toda a Europa, no mesmo período, era esse o espírito do tempo; à direita e à esquerda. As artes populares eram vistas - a par de elementos mais prosaicos como a bandeira e o hino ou de elementos mais sofisticados como mitos de origem ou ideias de um passado comum - como um dos aspectos fundamentais do kit "faça você mesmo" que, segundo Orvar Löfgren (1989), é requerido pelas identidades nacionais modernas. Ter uma arte popular - mesmo que tivesse de ser inventada - era fundamental para que um país fosse admitido no concerto das nações, como de resto mostram as Exposições Universais e o relevo nelas concedido à arte popular. O MAP é um produto idiossincrático desse estado de espírito, onde ser-se tradicional era uma pré-condição para se ser moderno, como mostrou a pesquisa de Vera Alves (2007) sobre o SPN/SNI.

É desta articulação contraditória entre tradição, nacionalidade e modernidade que nasce o MAP. Nele, o moderno e o tradicional misturam-se. O desenho do edifício e os murais das diferentes salas são estilizações modernistas de elementos populares. E, se os objectos que povoam as diferentes salas são tradicionais - embora não forçosamente autênticos -, o contexto em que eles 
são reapresentados é moderno. Quanto ao objectivo último do todo que era o MAP - a nacionalização do gosto das classes médias -, não podia ser mais moderno, com também mostrou a pesquisa de Vera Alves (2007).

Em condições normais, o MAP - tal como existia antes de ser encerrado não teria chegado até nós como chegou. Mas, por uma mistura ironicamente feliz de incúria e de inércia, sobreviveu ao seu tempo e é hoje um testemunho - raro na Europa - de um estado de espírito que, quer se goste quer não, participou da formatação do gosto moderno pelo popular.

Nesse sentido - regressando ao meu primeiro argumento -, o MAP é um lugar de memória. Num tempo em que tudo é património, o MAP é património e deve ser preservado. O que estou a sugerir é que o MAP deve continuar, mas como uma espécie de metamuseu, ou, se se quiser, como um museu de si próprio. Isso exigiria escolhas estratégicas ao nível museográfico. Talvez nem todas as salas sejam para conservar, dada até a sua desigual valia: a sala do Minho é única no seu valor decorativo e documental; já as salas sobre o Sul são menos conseguidas. Sobre o que lá está teria de ser construído um percurso expositivo que propusesse um olhar crítico sobre o museu, que o mostrasse como o resultado cenográfico de um determinado olhar sobre as culturas populares. Mas, independentemente dessas escolhas museográficas, o MAP deve continuar.

Ele é de resto uma peça essencial ao equilíbrio cénico desse outro lugar de memória que é a Praça do Império, um lugar único em Portugal pela sua capacidade para, num mesmo espaço, juntar tantas camadas contraditórias da história e da cultura portuguesa: guerreiros lusitanos e um planetário; o estilo manuelino e os Távoras; um jardim tropical e um museu de marinha; sonhos desfeitos de grandeza imperial e paradas da Guarda Nacional Republicana; turistas, famílias com crianças, arrumadores de carros e pescadores de domingo; a adesão à União Europeia e a arte moderna; pastéis de nata e McDonald's. E o Tejo. Sobretudo o Tejo.

Os modernos - entre os quais os modernos do MAP - concebiam os seus projectos de emblematização das culturas populares a partir da categoria da autenticidade: o povo era aquilo, aquilo era autêntico. Claro que o povo não era necessariamente aquilo e claro que aquilo não era necessariamente autêntico. Nesse sentido, o MAP é um híbrido: um lugar onde se misturavam diversos tempos - o tempo supostamente imóvel dos camponeses e o tempo moderno da construção autoritária das nações -, diversos objectos - objectos populares "genuínos", objectos populares encomendados, miniaturas, ampliações, murais de artistas modernistas -, diversos grupos sociais - o povo, etnógrafos estetas, as classes médias.

Esta hibridez constitutiva do MAP funcionou durante muito tempo como um handicap para o museu, acusado de privilegiar a cenografia em detrimento da exactidão etnográfica. Não deixa de ser verdade. Mas hoje sabemos que a hibridez é a característica fundadora de qualquer discurso sobre o popular. 
O popular é - literalmente - o produto do encontro de duas culturas: a cultura que lá estava e que não sabia que era popular e a cultura de quem chega lá e a nomeia como popular. No preciso momento em que qualquer objecto é discursado como popular - no preciso momento em que alguém diz dele "isto é popular" -, esse objecto viu serem somados novos significados aos seus significados originais, tornou-se um objecto literalmente híbrido ao qual foi acrescentada, para citar Barbara Kirshenblatt-Gimblett (1998), uma "segunda vida”, uma nova carreira, novos públicos, novas funções, novas potencialidades.

Durante muito tempo essa capacidade de criar - sem saber - objectos híbridos a partir das culturas populares foi um privilégio das elites letradas. Eram elas que decidiam que objectos de arte popular - um galo de Barcelos ou uma escultura do Franklin - mereciam figurar como objectos de colecção ou, pelo contrário, como bibelôs de gosto duvidoso. Elas é que decidiam se a dança X era verdadeiro folclore ou se pelo contrário a dança Y era "um falso".

Mas a história da parte final do século XX é também a história da democratização do popular. Essa história foi contada para a América Latina por autores como García Canclini (1998) ou David Guss (2000). E é inseparável da assunção - pelos criadores populares - da hibridez constitutiva do popular nos termos em que García Canclini fala dela. Um popular vivido não já como "complacência melancólica para com as tradições", mas como um projecto criativo em que os recursos tradicionais se misturam deliberadamente com novos formatos; um popular em que a experimentação e a procura de novas soluções se tornou a norma; um popular onde as velhas distinções entre tradicional e moderno, popular e erudito ou arte e artesanato são postas de parte. Redefinidas desta forma, as culturas populares passaram a integrar tanto projectos de experimentação artística individual como propostas alternativas articuladas por activistas comunitários que - quando correm bem (e nem sempre correm bem...) - operam como fonte de orgulho identitário e de prosperidade material para as comunidades.

O espaço do MAP - nascido ele próprio de uma concepção malgré soi híbrida da cultura popular - é também o espaço ideal para essas novas culturas populares. Este é o meu segundo argumento: museu de si próprio, o MAP pode também tornar-se uma plataforma contemporânea de diálogo com essas novas formas da cultura popular. Sendo um lugar de memória, o MAP pode ser simultaneamente um lugar de futuro. Não se trata só de musealizar parte do que lá está, trata-se de pôr fim à total ausência de projecto que caracterizou este museu nas últimas décadas e abri-lo aos novos discursos sobre o popular que caracterizam a contemporaneidade. Através de exposições temporárias, da consolidação de programas de trabalho com museus etnográficos locais e com outros activistas culturais, através do lançamento de oficinas e iniciativas 
abertas à experimentação com a matéria do popular, o MAP poderia tornar-se um lugar de convergência e confronto entre discursos sobre e a partir das culturas populares. A sua exposição de reabertura tanto poderia ser uma exposição de cartazes, websites e tee-shirts de festas de padroeiro, como um "best of" do novo artesanato criado à sombra dos programas do Instituto do Emprego e Formação Profissional. Poder-se-ia pensar em montar uma exposição em torno dos graffiti urbanos, que juntasse artistas portugueses e experiências internacionais. E porque não pôr lado a lado António DaCosta - e os seus quadros sobre as Festas do Espírito Santo nos Açores - e os vestidos exuberantes das "queens" dos Holy Ghost Festivals da Califórnia? Porque não propor a artistas e a artesãos instalações a partir de tal ou tal tema da cultura popular? Porque não pensar num "estado da art brut" em Portugal e dos seus diálogos com o imaginário popular?

A missão deste MAP visto como lugar de futuro seria em todo o caso libertar as novas formas da cultura popular de visões assentes no preconceito, afirmando-as como lugares de criatividade. Há ainda em Portugal uma solenidade na abordagem do popular que tem dificultado a inovação e a experimentação. Mas isso só torna mais necessária esta reorientação do MAP.

O Ministério da Cultura está já convertido - UNESCO oblige - aos méritos do património imaterial. É pena que o Ministro da Cultura tenha ainda dificuldades em entender que o património imaterial é tão-só a nova expressão - politicamente correcta - para designar algumas das múltiplas formas daquilo a que costumamos chamar cultura popular. Quando o entender, voltará certamente atrás na decisão de acabar com um museu - o MAP - que pode ser um ponto nevrálgico na articulação das acções a desenvolver em Portugal em torno da salvaguarda e da dinamização do património - imaterial e material - das culturas populares.

\section{BIBLIOGRAFIA}

ALVES, Vera, 2007, “Camponeses Estetas” no Estado Novo: Arte Popular e Nação na Política Folclorista do Secretariado de Propaganda Nacional. Lisboa, ISCTE, tese de doutoramento.

AUGÉ, Marc, 2006, Não-Lugares: Introdução a uma Antropologia da Sobremodernidade. Lisboa, Editora 90. .

CANCLINI, Nestor García, 1998, Culturas Híbridas. São Paulo, EDUSP.

GUSS, David, 2000, The Festive State. Berkeley, University of California Press.

KIRSHENBlATT-GIMBLETT, Barbara, 1998, Destination Culture. Berkeley, University of California Press.

LÖFGREN, Orvar, 1989, "The Nationalisation of Culture”, Ethnologia Europaea, XIX: 5-24.

LOWENTHAL, David, 1998, The Heritage Crusade and the Spoils of History. Cambridge,

Cambridge University Press.

NORA, Pierre (dir.), 1984, Les lieux de mémoire. Paris, Gallimard. 


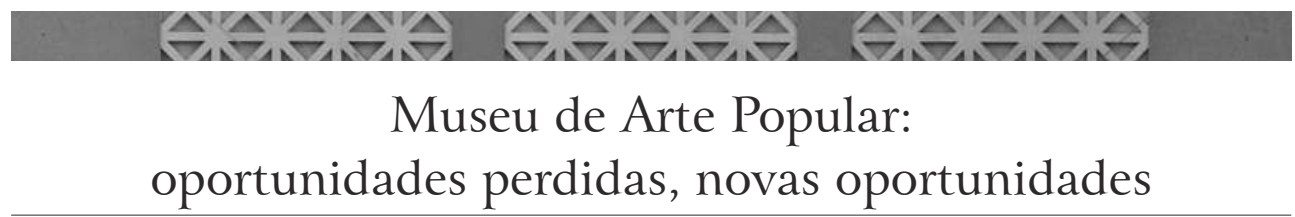

Paulo Ferreira da Costa

CRIA

\section{$H_{\circ}^{i}$} istória e memória

O debate em curso (2006-2009) sobre o Museu de Arte Popular constitui-se actualmente como um dos mais férteis terrenos para a reflexão sobre o património etnológico, em particular para as áreas disciplinares nele mais directamente implicadas - a museologia e a antropologia. Não obstante as diversas variantes até agora enunciadas, uma estratégia apresenta-se como predominante, assim sintetizada no último boletim do ICOM: a da "Reabertura do MAP no seu lugar próprio, devidamente modernizado, mas respeitando a colecção e o conceito original" (n. ${ }^{\circ}$ 5, Jun/Ago de 2009, p. 13).

Trata-se de uma estratégia de (re)valorização patrimonial assumidamente de vocação historicista (fundada na história da arte, da arquitectura, do design, da antropologia e do Estado Novo) e que privilegia o facto de o MAP ter permanecido praticamente inalterado, desde a sua fundação, no que respeita ao seu imóvel, ao seu património integrado e móvel, ao seu discurso e equipamento museográfico primitivos, como reflexo de políticas e medidas de um determinado período (histórico, político, cultural e científico). Sendo lugar de memória bom para pensar e ensinar muitas coisas sobre aquele período e alguns dos seus protagonistas e ideias, o MAP revela-se, pois, para utilizar a expressão de João Leal, com vocação para "museu de si próprio".

Sendo patrimonialmente válidos os argumentos que configuram esta estratégia, o que considero particularmente interessante, para a reflexão suscitada por aquele debate, é o plano secundário a que as colecções do MAP nele têm sido remetidas, designadamente quando considerado que as colecções constituem a razão primacial da existência de um museu e, como tal, o factor primordial em função do qual se definem a sua missão e as estratégias de gestão daquelas. Ora, neste debate, (quase) tudo se passa como se a restituição do MAP à sua condição física original (ainda que paralelamente a outras componentes de actuação) devesse ser feita apesar das colecções com que se articulou a missão de que foi originalmente investido e que, até à criação do Museu Nacional de Etnologia (MNE), em 1965, o afirmaram certamente como o mais proeminente museu etnográfico em Portugal.

Precisamente por se tratar de um museu etnográfico, parecem-me constituir particular matéria de reflexão muitos dos discursos sobre as suas colecções, entre os quais os que persistem em classificá-las como "arte popular", 
não obstante a grande diversidade de tipologias materiais ali representadas, e recorrendo a esse polissémico ainda fortemente eivado dos sentidos que lhe imprimiu a etnografia ao tempo do SPN, como conceito genericamente aceite e plenamente operatório no actual contexto científico. Paralelamente, é matéria para reflexão o conjunto de dúvidas e certezas que desde há muito circulam sobre a autenticidade dessas 13.000 peças e que, a par da escassa documentação que as acompanha, por vezes se constituem como premissas para o seu entendimento como objectos etnográficos menores e, acima de tudo, reforçam a concepção de que no MAP tudo era discurso e ideologia do SPN. Parece-me que esta perspectiva deverá ser interrogada sob um duplo prisma: por um lado, considerando que o actual quadro de exigência ética, técnica e científica para a constituição e documentação de colecções não poderá ser aplicado retroactivamente no contexto do MAP, como aliás também não o pode no caso de quaisquer outras colecções; por outro lado, tomando como pressuposto evidente que, independentemente da sua maior ou menor polissemia, os bens patrimoniais são invariavelmente objecto de um discurso específico e decorrente de um determinado contexto de intenções e contingências.

$\mathrm{Na}$ ausência de quaisquer contributos por parte dos anteriores responsáveis directos das colecções do MAP sobre esta questão, apenas o MNE poderá esclarecer em definitivo este universo discursivo, na qualidade de seu depositário e no âmbito do trabalho de conservação e documentação em curso. De qualquer modo, até que se verifique esse esclarecimento, o que parece evidente é que tais argumentos não podem constituir-se como premissas para a reposição total ou parcial do discurso museográfico original do MAP, ignorando a relevância patrimonial das suas colecções no seu âmbito disciplinar evidente.

\section{História e estratégia}

Num âmbito especificamente museológico, de procura de uma alternativa para o destino anunciado para o MAP desde 17/5/2006, articulando as suas componentes de maior perenidade e valia patrimonial, i. e., o seu edifício e colecções, a própria história do museu encerra uma das soluções possíveis para a sua revalorização, provavelmente a mais avisada e a de maior relevância não apenas para aquelas componentes, mas também para as mais importantes colecções etnográficas nacionais consideradas globalmente. A lição que a história do MAP encerra é, aliás, dupla.

Em primeiro lugar, tal como frequentemente referido no debate em curso, o MAP permaneceu como tal até recentemente (i. e., às obras de fundo iniciadas como etapa indispensável do seu processo de requalificação) pela ausência de projecto alternativo ao projecto original, com excepção do esboçado em dois momentos recentes da sua história (1993-1997 e 1999-2006), em ambos os casos a partir do exterior do MAP, mas cuja concretização foi impossibilitada por constrangimentos de ordem diversa. $\mathrm{O}$ museu não permaneceu como 
museografia de época por mérito próprio, mas sim pela ausência de um projecto sustentado para ele.

Em segundo e mais importante lugar, em dois momentos da história do MAP e do Portugal moderno, aquele foi objecto específico de políticas culturais ambiciosas, não lhe dirigidas em exclusivo, mas reconhecendo a sua importância patrimonial e convocando a sua participação num quadro mais amplo e sistémico de valorização do património etnológico.

Em 1979, pouco antes da implementação do IPPC, o Decreto-Lei n. ${ }^{0}$ 535/79 cria o Instituto-Museu Nacional de Etnologia (I-MNE), como entidade que agrega o Museu de Etnologia (ME), os Centros de Investigação que lhe estão directamente na origem - Centro de Estudos de Etnologia (CEE) e Centro de Antropologia Cultural e Social -, o MAP e as colecções etnográficas do Museu Nacional de Arqueologia (MNA), na perspectiva da institucionalização das longas relações de facto entre o ME e aqueles Centros e, entre outras virtualidades, na assunção do papel que o I-MNE poderia desempenhar como núcleo de apoio aos emergentes museus etnográficos locais, papel que, não obstante aquele diploma não ter entrado em vigor, efectivamente cumpriu a partir da década seguinte.

Resultando de um projecto do próprio ME, à data dirigido por Ernesto Veiga de Oliveira, a criação do I-MNE visava assim dar corpo a uma estratégia de reorganização das mais relevantes colecções etnográficas públicas nacionais, com vista a completar lacunas (tipológicas e cronológicas) mútuas. Na perspectiva da procura de uma alternativa para o destino traçado desde 2006 para as colecções do MAP, a estratégia de 1979 parece consistir num forte indicador qualitativo sobre estas, sobretudo quando considerado o papel desempenhado pela equipa fundadora do MNE na valorização da cultura material tradicional portuguesa, de cujo conhecimento e documentação, através de pesquisas no terreno, cartografia sistemática, constituição de arquivos públicos e divulgação editorial e expositiva foi o principal agente.

Frustrado o esforço de que resultou o Decreto-Lei n. ${ }^{0}$ 535/79, em 1989 este é parcialmente tomado como inspiração no âmbito de nova medida. Corresponde esta ao enunciado no Decreto-Lei n. ${ }^{\circ}$ 248/89, que novamente reúne sob a coordenação do MNE as colecções etnográficas do MNA e o MAP, desta feita individualizado como Núcleo de Arte Popular, mas que desastrosamente retira ao MNE um dos seus Centros de Investigação, decretando um divórcio sob a forma de uma união de facto. De qualquer modo, independentemente dos vários erros que dela derivaram, esta estratégia parece-nos assentar sobre uma intenção de valorização do património etnológico, no âmbito da qual o IPPC acolheu simultaneamente sob sua tutela não apenas o próprio MNE mas também, culminando insistentes pedidos da Assembleia Distrital do Porto, o Museu de Etnografia e História do Douro Litoral, então renomeado Museu de Etnologia do Porto, na perspectiva da sua requalificação futura. Paralelamente, 
a colocação sob a tutela do MNE das colecções etnográficas do MNA visou circunscrever a actuação deste à sua área disciplinar de enquadramento, em consonância absoluta com a sua missão e prática exclusiva desde há décadas.

Ao invés de outros olhares, não me parece que ambos os projectos/medidas traduzam um qualquer incómodo face às origens do MAP, sobretudo no caso do primeiro, o único verdadeiramente concertado pelo contexto institucional de então e resultante de uma visão solidamente documentada sobre as suas colecções. Antes parecem - apesar dos contraciclos de falta de vontades e/ou de meios que impediram a sua concretização - enunciar um desejo genuíno de impedir uma tragédia já então anunciada para o MAP, reinventando-o para assegurar a sua sobrevivência, adaptando-o a novos enquadramentos disciplinares, a novas exigências técnicas, e não encarando a sua integração na instituição museológica de referência nacional no âmbito do património etnológico senão como oportunidade para a valorização das suas 13.000 peças, representativas de tipologias muito diversas, e não apenas de carácter "artístico" ou de valor predominantemente estético. Esta seria a oportunidade também, já subjacente ao projecto inicial expresso no Decreto-Lei n. ${ }^{\circ}$ 535/79, de dotar o MNE de um pólo dedicado à cultura tradicional portuguesa na frente ribeirinha de maior afluência de públicos da cultura, eixo do qual persiste em não beneficiar desde a sua inauguração em 1976, apesar da relativa proximidade.

É este, pois, um outro possível contexto histórico para a definição de estratégias para o MAP, não a partir da ideologia e estéticas do SPN e do Estado Novo, mas a partir da visão, dos princípios metodológicos e boas práticas que caracterizaram a actuação da equipa fundadora do MNE. Esta é inegavelmente merecedora de lugar de relevo na memória da antropologia, do património e da museologia: pelo modo como reinventou a primeira, precisamente no contexto de predominância da etnografia do SNI (note-se que o CEE é criado no ano anterior à inauguração do MAP); pelo modo como contribuiu para o conhecimento do património etnológico e a dignificação do seu estatuto; enfim, pelo modo como se assumiu, através do inovador e qualificado projecto do Museu Nacional de Etnologia, como referência na actividade museológica, e não apenas em Portugal. 